\title{
QIKJS-Part.II.F
}

\section{Qualitative Inquiry of Korean Judicial System}

\author{
Kiyoung Kim \\ Professor of Law and Public Policy \\ Dept. of Law, Chosun University \\ Gawng-ju South Korea
}

\section{Introduction}

Shoenberg once admonished by interrupting a ferment debate to the truths, "you are right since you are younger." The right or wrong may be some ultimate dimension that the researchers, a lonely seaman on the work of knowledge building, would be disposed to drift. It casts a thread to see the kind of trait in reflexivity of our lifetime passage. It is, one sense, that the young people would be a better audience to appreciate and receive the findings or discussions and arguments although the notion is relative. Given the young people normally are healthier, it also corroborates the words of legacy that the medicine would be an idealistic yardstick to measure the aesthetics or artifacts as well as the archaeology of knowledge. The two methods entail this kind of trait. For example, the quantitative researchers have to analyze, discuss and desirably advance to the implications or suggestions relating with their findings beyond the simple nature of math or statistical dependence. Given the stronger quality of the above trait within the qualitative inquiry, however, Shoenberg's admonition is more likely immediate that the qualitative researchers can sense (Patton, 2002). His word may also be related with the debate of structured or unstructured approach within the qualitative method. The unstructured approach is literally noted as beginning the research work as unprepared or off hand without a premeditated structure basing and controlling his research process and operation. The structured approach is vice versa that the researchers generally depend on the structure he contemplated and designed before embarking on his research activities. Although the knowledge claims may be judged more properly by the fresh researchers or college graduates, ${ }^{1}$ his word may not be thorough when we consider the merits of structured and unstructured approach. That is because various factors or situational variances could intervene beyond the medical standard of audience.

I have enjoyed a newly released Korean film titled "the Himalayas" with my family. The story is non-fictional about the professional mountain climbers, who had been teamed to

\footnotetext{
1 This may be a part of reason that the law schools administer the student-run law reviews.
} 
climb the world highest located in the titled mountains. A prima in the story was H.K. Uhm, who has a world record of successful mounting on the top of 16 peaks. He had been an impressive team leader over the decades, and bred his protégés, who were young and ambitious. Shortly upon his retirement, three young climbers, so prospective as one of next prominent heroes, unfortunately frustrated around the death zone of 7,770-7880 meters, and eventually were frozen to death. He decided to risk such dangerous search activities for the dead bodies of his disciples, and later kept a promise with them by winning the world record despite his retirement. It moved us much because of deep humanity and tears of climber's society (Turner, 1975). In this way, the approach of social scientists can be that the young minds are not always better. The experience and knowledge about a route, ways to resist sudden snowfalls, or night stay on the cliffs and on, can be more available or readier for the seniors to survive. I suppose the structured or unstructured approach depends on the wisdom and career experience that the researchers need to be scrupulous to appreciate fully the nature of his research. Since it is a matter of extent, we may be more realistic to use more and less structured approaches as Maxwell guided. Both approaches can be compared in aspects to bring a difference in terms of research operation. Let me present a part of their consequence to explore the merits of them.

\section{Less Structured and More Structured}

A general institution is that the less structured approach is more appropriate to the qualitative method since it is inductive, flexible over the research process and can create methodological "tunnel vision" for complete stories. With the emerging insights and rigors to exhaust the possible data, the less structured approach (LSA) is contrasted with more structured approach (MSA) or substantial prior structuring (Maxwell, 2005).

The internal validity and contextual understanding can be reinforced with a less structured approach since the researchers are less predisposed with the generizability and comparability. They do not trade with them in advance, and can be more faithful to the fields or realities. The local causality occurs that the researchers can be more agile or productive to reveal the processes and arrive at specific outcomes.

Highly inductive or loosely structured approach, however, can lead to uneconomical consequences given no prestructured habor of researchers has been a stimulus to prompt their plan. Extremely within the LSA, the mindedness or dimension could be the kind of open or absent minded newspaper reporters in any exotic war field as dependent on the exterior development. It can be factually convivial or faithful to the field, but can produce a few banalities hardly of scholarly construction.

I generally have been impressed with the Maxwell's view and practical suggestion (i) all researchers have an implicit decision on his research design and the debate between LSA 
and MSA just relates with his mindedness or visualization into some explicit decision (ii) the best strategy will be detailed tentative plan and leaving out the possibility of revising them (2005). A most challenge involving the researcher's inattention with merely an implicit decision arises that he or she could not systemically appreciate the consequences possibly deviant from his original intent through answering the research questions, advancing the goals and time or energy saving.

The more structured approach can be suited to the multi-site investigation than is appropriate to the single site approach. Given the multi-site investigation needs of moving among another and comprehensive schedule on the research operation, the MSA is necessary to actualize their plan within the time frame. It also can allow the research hard and tight than soft or loose as Miles and Huberman's suggested (1994). Nevertheless, this never should be one-dimensional implications, and another point of consideration is how the prestructuring is used beyond the amount of prestructuring.

Given the approach can vary, more strategic is it that we will explore the components of qualitative research and what are the challenges that the researchers might unthink (MSA) or rethink (LSA) to address in order for a successful research. In the qualitative studies, four main components need to be considered to reinforce and justify regardless of structured or unstructured approaches. They include the research relationships, selection of settings or individuals, data collection and data analysis, in which I will talk about some of them. It is important to consider how the researcher effectively negotiates the research relationships. The relationship in the fieldwork may be the kind of body-contact sport that poses a variety of challenges, such as gatekeepers. The intimacy or normal friendship may not work so that the researchers could be tougher even with his own social world. The rapport and reflexivity is, therefore, a vantage point that the researchers can sensibly get through his research goals. It needs to be noted that the kind of rapport than its amount is also important and the relationship is a complex and changing entity so that the researcher may impel to adjust with their prior structure. This implies that the interview in qualitative method is an interactive process very engaged intellectually and conducted with respect to revealing anything deeply personal (Rubin \& Rubin, 2005).

One caution can be relevant with our debate that the structured approach should not be an advocacy of any particular type of relationship, such goals as equality and participation. Instead, the qualitative researchers need to consider the particular context. Given its ultimate matter of politics, not technique, the perpetuation of existing power relationships is the point of consideration for the progressive researchers. This does not say that the unstructured approach will be more progressive, but suggests that the prestructuring has to be prepared in deep appreciation of the particular context than blindly preferring the dominant humanitarian and demographic agenda (Maxwell, 2005). 
In consideration of your approach, the tips fairly deserve a deep mindfulness about the purposes and assumptions you bring to relationship between the researcher and participants. The researchers on LSA can reinforce through thinking, for example, if the researcher identity could properly bracket the collection of field data and analysis or memo in self-reflexivity can be used to help you become aware of many situational relationships. The researchers on MSA can inquire if his predisposition might be biased by reconsidering, for example, "if I hold unexamined stereotypes about the participants (2005)."

In terms of selection decisions, the two kinds of approach can have strengths and weaknesses. The LSA can work effectively to respond with unexpected impediment so that the details need to be kept flexible or open. For example, the researcher may retreat that the selection of juniors could be the only choice although his initial plan triggered sophomores and seniors for optimal diversity of views (2005). This was not expected in the prestructuring, but can be realized only after she consulted with members of the department. The researchers on MSA also need to be adequately exposed to the kind of challenges, such as key informant bias.

In extreme cases, the researchers may be ousted of his expectations that some culture, settings and relationships make it inappropriate or unproductive to conduct interviews or even to ask questions (2005; Miles \& Huberman, 1994). In this case, tightly structured, but unrealistic approach in that sense, can be problematic. The researchers may need to take an apprenticeship to confront such challenges or substantially rethink his ways of negotiating a relationship or conducting the data collection. The loosely minded researchers would be more problematic causing them much cost for the inevitable prolongation of field work and even unprepared risks.

\section{LSA and MSA on my Qualitative Research}

The debate on the LSA and MSA supposedly entails some relevance with the variety of qualitative inquiry frameworks. As we see, the qualitative method encompasses an extensive diversity of frameworks and even person to person ways of methodological approach based on the paradigmatic, philosophical and theoretical orientations. ${ }^{2}$ For example, my approach can be more closely affiliated with the GT approach and realism or phenomenology and heuristics as well the systems or complexity theory and hermeneutics. The systems or complexity theory can allow me to be more structured (hence MSA) since the stories and themes would be more static because of the Korean sources of scholarly writings

\footnotetext{
2 Therefore, themes can well cut across the inquiry traditions and frameworks so that even more general frameworks, such as ethnography, phenomenology, hermeneutics, narrative inquiry and complexity theory have mixed genealogies, multiple contributors, and disagreements among theorists (p. 159, Patton).
} 
on PAKJS. My basis in progressing on the kind of hermeneutics approach can be premeditated to correspond with the contents that will be produced in any meaningful order and that can be excavated through the interpretation and analysis. The systems theory would attend to interrelationship, perspectives and boundaries that would be integrated to support my research goals (Patton, 2002). The complexity theory is necessary if the PAKJS also has a trait requiring attendance to emergence, nonlinearities, dynamics and adaptation. The GT approach can be related with the philosophy of realism, in which we need to be sophisticated on the kind of inquiries, "what are the actual mechanisms that explain how and why reality unfolds as it does in a particular context?" The realism attributed within the GT approach can be served more faithfully that the researchers are an active participant and emancipate himself from the general attitude of intellectuals as the all-known analyst. The researchers engaged with the GT approach, therefore, would be open, sensory or even to be affected, humble, and participatory (Kim, 2015a,b,c,d). This can be made friendlier with the LSA, but with a caution not to go my original missionary merely passed out or even abandoned. The interviews and focus group meeting will be dense within the atmosphere that the kind of values as a best practice of qualitative method, such as rapport, open-ended questions, as well as deep inquiry, need more flexible structure of approach. Since my topic is closely twined with my professional background and lived experiences in Korea, the phenomenology and heuristics will step up with the TV news and daily newspaper articles or stories, and experience of peers on the law and Korean judicial system. Therefore, it will be least related with the MSA, but I still feel that some extent of organized strategy is necessary in order to pursue a theme in a scholarly way. A memoing and note taking seems helpful, and journal writing is one niche of stewardship for more scholarly experience of lives. 


\section{References}

Kim, Kiyoung, An Attempt on the Methodological Composure: Between the Number and Understanding, Nature and Construction (December 12, 2015a). K. Kim, An Attempt on the Methodological Composure: Between the Number and Understanding, Nature and Construction, Chosun University, 2015. Available at SSRN: $\underline{\text { https://ssrn.com/abstract }=2702701}$

Kim, Kiyoung and Ju, Hyun-Meong and Khatun, Marium, A Reflection on the Research Method and Exemplary Application to the College and University Rankings (October 23, 2015b). Kiyoung Kim, Hyun-Meong Ju, Marium Khatun. A Reflection on the Research Method and Exemplary Application to the College and University Rankings. Education Journal. Vol. 4, No. 5, 2015, pp. 250-262. doi: 10.11648/j.edu.20150405.23. Available at SSRN: https://ssrn.com/abstract=2686045

Kim, Kiyoung, Concerning the Research and Science (April 10, 2015c). Available at SSRN: https://ssrn.com/abstract=2592858 or http://dx.doi.org/10.2139/ssrn.2592858

Kim, Kiyoung, The Research Design and Methodologidal Deliberation (December 23, 2015d). Available at SSRN: https://ssrn.com/abstract $=3305760$

Maxwell, J. A. (2005). Qualitative research design: An interactive approach (2nd ed.). Thousand Oaks, CA: Sage Publications.

Miles, M. B., \& Huberman, A. M. (1994). Qualitative data analysis: An expanded sourcebook (2nd ed.). Thousand Oaks, CA: Sage Publications.

Patton, M. Q. (2002). Qualitative research \& evaluation methods (3rd ed.). Thousand Oaks, CA: Sage Publications.

Rubin, H. J., \& Rubin, I. S. (2005). Qualitative interviewing: The art of hearing data (2nd ed.). Thousand Oaks, CA: Sage Publications.

Turner, V. (1975). Drama, fields, and metaphors. New York, NY: Cornell University Press. 